\begin{tabular}{|l|l|}
\hline & \\
\hline
\end{tabular}

SEÇÃO: OUTROS TEMAS

\title{
A gestão educacional e a inclusão da temática ambiental nos PPPs de escolas públicas municipais
}

\author{
Educational management and the inclusion of environmental themes in PPPs of \\ municipal public schools
}

\section{Maria Tereza Rocha \\ Ramos $^{1}$ \\ orcid.org/0000-0003-2480-4911 \\ terezaviana_3@hotmail.com \\ Patricia Diana Edith \\ Belfort de Souza \\ e Camargo Ortiz \\ Monteiro ${ }^{1}$}

orcid.org/0000-0002-2944-9050

patyortizmonteiro@terra.com.br

Recebido em: 20 ago. 2018. Aprovado em: 19 ago. 2021. Publicado em: 21 jan. 2022.
Resumo: A presente pesquisa tem como objetivos: (a) compreender como foram elaborados os projetos político-pedagógicos (PPPs) de quatro escolas de ensino fundamental, públicas, localizadas em um municipio do sudoeste da Bahia, e (b) conhecer como é abordada a temática educação ambiental (EA) nas matrizes curriculares desses projetos. Foram analisados quatro PPPs, de quatro escolas municipais que atendem aos anos iniciais do ensino fundamental. Além disso, foram realizadas entrevistas semiestruturadas com 27 professores. O estudo é de natureza qualitativa, descritiva e exploratória. Foi realizada análise documental dos PPPs e, ainda, a categorização dos textos desses documentos, utilizando-se o software IRAMUTEQ. A triangulação dos dados foi realizada segundo Minayo (2010). Dos quatro PPPs analisados, três apresentam matrizes curriculares que contemplam a temática EA sob uma perspectiva conservacionista, e um aborda a inserção da EA em uma perspectiva socioambiental.

Palavras-chave: educação ambiental, projeto político pedagógico, gestão educacional

Abstract: The present research aims: (a) to understand how the political-pedagogical projects (PPPs) of four public elementary schools, located in a city in southwest of Bahia, were developed; and (b) to learn how environmental Education $(\mathrm{EE})$ is approached by the curricular matrices of these projects. Four PPPs were analyzed from four municipal schools that attend the initial years of elementary school. In addition, semi-structured interviews were conducted with 27 teachers. The study is qualitative, descriptive and exploratory. A documentary analysis of the PPPs was carried out, as well as the categorization of the texts of these documents, using the IRAMUTEQ software. The triangulation of the data was done according to Minayo (2010). Of the four PPPs analyzed, three present curricular matrices that consider the theme EA from a conservationist perspective, and one approaches the insertion of EE in a socioenvironmental perspective.

Keywords: environmental education, political pedagogical project, educational management.

No mundo globalizado em que vivemos, com as crescentes mudanças sociais, políticas e econômicas, a escola precisa se adaptar aos grandes desafios da sociedade contemporânea. Segundo Morin (2000, p. 35), nesta era planetária, para articular e organizar os conhecimentos, reconhecer e conhecer os problemas do mundo, é necessário reformar o pensamento.

Por meio da gestão democrática da escola, os projetos político-pedagógicos devem ser construídos coletivamente, com a participação de todos os atores, fazendo com que se sintam corresponsáveis pelo 
processo educacional. Sendo um instrumento de fundamental importância para a escola, precisa ser elemento norteador da organização pedagógica, visando ao sucesso na aprendizagem dos alunos, finalidade maior da escola como instituição social.

A educação ambiental (EA) é uma temática de grande relevância e que precisa estar inserida no contexto educacional como tema transversal, uma vez que não é possivel conceber uma educação comprometida com a continuidade da vida humana desacompanhada de sua dimensão ambiental, social, politica, econômica e cultural.

Nos Parâmetros Curriculares Nacionais (PCNs), de 1998, a educação ambiental está inserida como tema transversal nos currículos do ensino fundamental. Assim como a Lei 9.795/99, referente à Política Nacional de Educação Ambiental, em seu art. 10, afirma a necessidade da interdisciplinaridade para a EA, em seu artigo 10:

A Educação ambiental será desenvolvida como uma prática educativa integrada, contínua e permanente em todos os niveis e modalidades de ensino formal. $\$ 1^{\circ} \mathrm{A}$ Educação ambiental não deve ser implantada como disciplina especíica no currículo de ensino. (Brasil, 1999)

Além disso, o Plano Nacional de Educação, Lei $n^{\circ}$ 10.172/01, concebe a EA como tema transversal, pensando em um currículo integrado. Em seu artigo 28, determina: "A Educação Ambiental, tratada como tema transversal, será desenvolvida como uma prática educativa, integrada, contínua e permanente, em conformidade com a Lei $n^{\circ}$ 9.795/99" (Brasil, 2001).

Na Base Nacional Comum Curricular, a EA se apresenta sobre duas perspectivas: como modalidade da Educação básica e como tema especial. A EA como modalidade da educação básica está inserida dentre as demais áreas. Vale dizer que para cada modalidade é apresentada uma legislação específica. No caso da EA, a legislação apresentada são as Diretrizes Curriculares de Educação Ambiental (Brasil, 2016). Já os temas especiais são abordados como questões de importância social, na perspectiva de uma formação humana integral, inter-relacionando os componentes curriculares ao objetivo de "superar a lógica da mera transversalidade, ao se colocarem como estruturantes e contextualizadores dos objetivos de aprendizagem" (Brasil, 2016, p. 47).

Ao representar a constante transformação da realidade no cotidiano escolar, os PPPs precisam relacionar a teoria à prática, sempre em um movimento de ação-reflexão-ação. A escola precisa, de fato, preocupar-se em garantir a aprendizagem dos alunos, partindo de um planejamento pautado nas reais necessidades do educando, e a EA deve estar inserida nesse documento curricular, no contexto da prática e da realidade da escola.

Dado esse contexto, a presente pesquisa tem como objetivos: (a) compreender como foram elaborados os PPPs de quatro escolas de ensino fundamental, localizadas em um municipio do sudoeste da Bahia, e (b) conhecer como é abordada a temática educação ambiental (EA) nas matrizes curriculares desses projetos.

\section{A gestão educacional: um breve histórico}

Para compreender como se deu a concepção de gestão educacional, é importante considerar as abordagens histórica, política e social, desde os povos primitivos, compreendendo, assim, suas modificações.

\begin{abstract}
O primeiro momento dos últimos cinco séculos da nossa história registra precisamente o encontro ou desencontro de dois mundos (...) Encontro entre o mundo dos donos da casa e o mundo dos visitantes. O mundo dos povos nativos e o mundo dos povos latinos. O mundo dos conquistados e o mundo dos conquistadores. (Sander, 2005, pp. 92-93)
\end{abstract}

Esse movimento histórico da humanidade está associado a poderosos processos de expansão e mundialização: expansão da propriedade e do comércio, expansão do poder, expansão da fé.

Mais tarde, no século XIX, deu-se o segundo momento da nossa história educacional. Com a república, Benjamim Constant liderou uma reforma educacional alicerçada nos princípios doutrinais do positivismo francês, protagonizado por Comte, enfatizando noções de ordem e progresso, equilibrio e harmonia, deixando permanentemente suas marcas em nossas instituições políticas e sociais, e, segundo Sander (2005, p. 
97), o autoritarismo centralizador da administração pública se repetia na administração escolar.

Todo esse movimento político, social e econômico do século XIX impactou diretamente o campo educacional, e a gestão educacional, apresentada sob o ponto de vista administrativo, teve como prevalecentes idéias centralizadoras e autoritárias, que atingiram a dinâmica escolar.

Sander (2005) considera que, no contexto mais amplo do mundo ocidental, no século $X X$, o positivismo iluminou decisivamente as teorias clássicas de administração, em particular o fayolismo, dos franceses, o taylorismo e o fordismo norte-americanos e, mais tarde, o modelo burocrático weberiano dos povos saxões. Os movimentos gerenciais da escola clássica difundiram-se rapidamente por todo o mundo e invadiram as várias áreas temáticas da administração, incluindo a administração de ensino, bem como da educação brasileira. Segundo Aranha (1996, p. 213) "a adaptação do ensino à concepção taylorista, típica da mentalidade empresarial tecnocrática, exige (...) o planejamento e a organização do trabalho pedagógico com a devida especialização das funções e a burocratização".

No Brasil, o século XX foi marcado por grandes mudanças, sobretudo pelo fim da $1^{a}$ República, momento marcado por crise em todos os aspectos da sociedade brasileira. Além disso, outros eventos importantes foram a Semana da Arte Moderna, de 1922, em São Paulo, o momento da Escola Nova, em 1928, a Lei Francisco Campos, em 1932, a criação do Ministério da Educação etc. (Shiroma et al., 2011).

Após a Segunda Guerra Mundial, a educação passa a ser vista como um fator determinante de crescimento econômico, o principal instrumento de progresso técnico e o mais poderoso meio de seleção e ascensão social, havendo um crescimento significativo dos sistemas de ensino.

Nos anos 1970, os economistas da educação compreenderam que a dimensão econômica deveria ser guiada por outros fatores, de natureza política e sociológica, começando pela própria vontade política dos governos e pela continuidade do esforço educacional através dos anos.
Faltou, na verdade, aos desenvolvimentistas da educação brasileira compromisso prioritário e continuado com a formação para a cidadania, a defesa dos direitos humanos e a promoção da equidade e da participação popular (Paro, 2001).

Nos anos 1980, surge o Estado Democrático, com movimentos de escola plural, aberta e igualitária, na luta pelo processo de gestão democrática. E, por fim, a Constituição de 1988 estabelece que a educação é um direito de todos e um dever do Estado e da família. Sua finalidade é o pleno desenvolvimento da pessoa, seu preparo para a cidadania e sua qualificação para o trabalho (Brasil, 1988, art. 5). A Lei de Diretrizes e Bases da Educação Nacional (LDB), promulgada em 1996, retoma esse dispositivo, incluindo-o dentre os princípios e fins da educação nacional. Assim, tanto a Constituição quanto a LDB regulamentam a gestão democrática como princípio de ensino público, com a descentralização do processo de hierarquia.

\section{A gestão democrática na escola}

Nesse sentido, a gestão democrática dá abertura para a participação de todos os envolvidos no processo educacional, estabelecendo um relacionamento de colaboração e parceria com a equipe escolar, assim como com a comunidade onde está inserida a escola, ouvindo e respeitando as diversidades, e garantindo o bem-estar coletivo.

A gestão democrática ganhou corpo no con-
texto educacional acompanhando uma mu-
dança de paradigma no encaminhamento
das questões desta área. Em linhas gerais, é
caracterizada pelo reconhecimento da impor-
tância da participação consciente e esclarecida
das pessoas nas decisões sobre a orientação
e planejamento de seu trabalho. O conceito
de gestão está associado ao fortalecimento
da democratização do processo pedagógico,
à participação responsável de todos nas deci-
sões necessárias e na sua efetivação mediante
um compromisso coletivo com resultados
educacionais cada vez mais efetivos e signifi-
cativos. (Luck, 1997, p. 1)

A construção e a efetivação do PPP entre os sujeitos da escola demonstram a importância e a necessidade do trabalho em grupo, e a efetiva participação das pessoas na busca incessante por 
uma educação de melhor qualidade social para todos. Como destaca Luck (2008, p. 17), o "conceito de gestão está associado à mobilização de talentos e esforços coletivamente organizados, à ação construtiva conjunta de seus componentes, pelo trabalho associado, mediante reciprocidade que cria um 'todo' orientado por uma vontade coletiva".

É importante destacar que a promulgação da Constituição Federal de 1988 impulsiona novas expectativas de democratização do ensino, visando à conquista da autonomia da escola. Nesse sentido, a referida Constituição estabelece como princípios básicos de educação o "pluralismo de ideias e de concepções pedagógicas" e a "gestão democrática do ensino público" (Brasil, 1988, art. 206). Em se tratando do segundo principio, a participação coletiva deve prevalecer em todos sentidos, de modo que as pessoas envolvidas possam se sentir parte desse processo.

Trabalhar com a gestão democrática na escola impõe muitos desafios, como, por exemplo, respeitar e aceitar ideias divergentes, procurando a superação dos obstáculos por meio do diálogo, para a construção de propósitos comuns, garantindo a participação de todos os atores envolvidos.

Quanto à autonomia administrativa, configura-se, antes de tudo, como um ato político, na medida em que requer tomada de posição.

(...) a administração escolar, por não se resumir à dimensão técnica, mas por configurar-se como ato político, tem a sua trajetória reduzida, no bojo desta modalidade, a rotinização das atividades administrativas e burocráticas, secundarizando, desse modo, a compreensão mais abrangente do processo politico-pedagógico. (Dourado, 2000, pp. 82-83)

A escola pública hoje busca ter uma autonomia administrativa que possibilite tomar decisões democráticas, eficazes e condizentes com a lei que rege o âmbito escolar. Entretanto, por estar vinculada a uma hierarquia administrativa, nem sempre isso é possivel, prevalecendo tão somente a transmissão de ordens, determinações, normas e regulamentos. O reconhecimento de que em qualquer lugar onde se estabeleçam relações de hierarquia há manifestações de poder não é a questão fundamental. A questão fundamental é que esse poder seja legítimo, ou seja, que a maioria dos integrantes da instituição contribua para a sua formação, com a consciência de que deve ser utilizado em benefício da organização como um todo e do alcance de seus objetivos enquanto instituição. O estabelecimento de poder com base na discussão implica, portanto, consenso fundamentado em acordos e negociações.

\section{O projeto político-pedagógico como instrumento norteador da ação pedagógica}

O PPP da escola é um instrumento curricular considerado cultural e dinâmico, um documento construido na/pela escola, e que faz parte da gestão democrática, porque confere a possibilidade de todos os envolvidos compreenderem e analisarem a situação atual da instituição, projetando novas ações no sentido de superar, resolver e encontrar alternativas para muitos dos problemas encontrados no processo de problematização e contextualização da realidade escolar (Benincá, 2001).

Sobre os PPP, Veiga (2001) explica:

(...) é a valorização da identidade da escola e um
chamamento à responsabilidade dos agentes
com as racionalidades interna e externa. Esta
idéia implica a necessidade de uma relação
contratual, isto é, o projeto deve ser aceito
por todos os envolvidos, daí a importância de
que seja elaborado participativa e democra-
ticamente. (Veiga, 2001, p. 110)

A construção do PPP surge da necessidade de organização da escola, para que ela cumpra o seu papel de instituição formadora, responsável pelo desenvolvimento social, crítico, reflexivo do homem, por meio da educação.

O PPP faz parte do planejamento e da gestão escolar, mostrando a visão macro e a micro do que a instituição pretende ou idealiza fazer, seus objetivos, metas e estratégias permanentes, tanto no que se refere às suas atividades pedagógicas quanto às questões administrativas da escola. Veiga (2001, p. 13) cita que "a importância do Projeto Político-Pedagógico está no fato de que ele passa a ter uma direção, um rumo para as ações da escola. É uma ação intencional que deve ser definida coletivamente, com consequente compromisso coletivo". 
A elaboração do PPP da escola representa o desenvolvimento de um processo educacional composto por diferentes vozes dos sujeitos da escola: educadores, funcionários, estudantes, direção, coordenação, pais. Esse processo também viabiliza, na escola, a possibilidade de todos os envolvidos compreenderem e analisarem a situação atual da instituição, projetando novas ações no sentido de superar, de resolver e de encontrar saidas/alternativas para muitas das problemáticas identificadas no processo de problematização e contextualização da realidade escolar.

O professor necessita ser ativo na construção, na execução e na avaliação do PPP da escola, pois isso compõe as atribuições docentes, e é a partir desse documento que se efetiva a ação do professor no planejamento pedagógico. A LDB (Brasil, 1996) preconiza a participação do professor na construção do PPP, uma vez que isso estimula a autonomia, a identidade e a organização da sua prática pedagógica.

O PPP é a ação de planejamento mais abrangente da escola, pois contempla o planejamento curricular, que consiste no conjunto de experiências realizadas para atingir os fins educacionais. Como propõem Moreira e Silva,

O curriculo não é um elemento inocente e neutro de transmissão desinteressada do conhecimento social. O currículo está implicado em relações de poder, transmite visões sociais particulares e interessadas. O currículo não é um elemento transcendente e atemporal - ele tem uma história, vinculada a formas especificas e contingentes de organização da sociedade e da educação. (Moreira \& Silva, 2001, p. 8)

Assim, é necessário que o professor conheça bem a proposta pedagógica da escola, para que ele possa desenvolver o planejamento pedagógico referendado ao PPP da escola. O desafio da escola, de acordo com Vasconcellos (2000), é recuperar o PPP da escola como necessário e possivel, como elemento de articulação da ação pedagógica, despertando no professor a necessidade de mudança.

É importante salientar que o PPP não é um documento pronto e acabado, mas está em constante processo de reestruturação, reavaliação, em um ato de ação-reflexão-ação, por meio do qual os sujeitos que fazem parte dessa construção coletiva podem se apropriar dos conhecimentos científicos, sociais e tecnológicos, ressignificando sempre suas histórias.

\section{Inserção da EA nas matrizes curriculares}

A Política Nacional do Meio Ambiente institui-se no Brasil através da Lei Federal n 6.938, de 31 de agosto de 1981, que, em seu art. $2^{\circ}$, inciso $X$, versa sobre a necessidade de a educação ambiental ser oferecida a todos os níveis de ensino, além de ser oferecida à comunidade, com o objetivo de capacitá-la na defesa do meio ambiente.

A Constituição da República Federativa do Brasil, promulgada em 5 de outubro de 1988, no art. 255, assegura a todos o direito ao meio ambiente ecologicamente equilibrado, garantindo a sadia qualidade de vida, impondo-se ao poder público a preservação das presentes e das futuras gerações.

A Conferência das Nações Unidas sobre Meio Ambiente e Desenvolvimento, realizada no Rio de Janeiro, em 1992 (ECO 92), aprovou o documento Agenda 21, que definia os compromissos assumidos pelos países participantes, tendo em vista a mudança do padrão de desenvolvimento no século posterior. A ideia era tornar possivel a construção de um plano de ação e de um planejamento participativo em nivel global, nacional e local, capaz de permitir, de forma gradual e negociada, o nascimento de um novo paradigma de desenvolvimento para o século vigente (Dias, 1992).

Em 1996, foram instituídas as Diretrizes e Bases da Educação Nacional, pela LDB, n 9.394/96, que, em seu art. 32, inciso II, exige para o ensino fundamental "A compreensão ambiental natural e social do sistema político da tecnologia, das artes e dos valores em que se fundamenta a sociedade" (Brasil, 1996, art. 32), e, no art. 36, os currículos do ensino fundamental e médio "(...) devem abranger, obrigatoriamente, (...) o conhecimento do mundo físico e natural e da realidade social e política, especialmente do Brasil" (Brasil, 1996, art. 36).

Em 1998, chegaram às escolas públicas brasileiras os Parâmetros Curriculares Nacionais (PCNs), do Ministério da Educação, que apresentaram, como um dos temas transversais, o meio ambiente. A escolha do meio ambiente como um dos temas transversais teve sua definição baseada 
em quatro critérios básicos: urgência social; questões de abrangência nacional; possibilidade de ensino-aprendizagem na educação fundamental e, por fim, o favorecimento da compreensão da realidade e da participação social. Conforme Carvalho (2004, p. 19), a EA pode ser entendida como

(...) uma ferramenta privilegiada para o estabelecimento de um novo contrato com a natureza baseado em uma conscientização mais profunda, tanto dos elementos que compõem o Meio Ambiente, onde o homem passa a ser um elemento-chave do contexto ambiental; quanto da necessidade de ver o meio Ambiente como condição maior da vida.

A escola assume um papel fundamental na formação de cidadãos responsáveis e ativos, resgatando valores essenciais como ética, fraternidade e respeito à vida, e a EA não poderia estar fora dessa discussão. Devido a sua abordagem holística e integradora, ela deveria ser trabalhada como tema transversal (Brasil, 1998). A legitimação dessa transversalidade implícita na temática ambiental representa um passo essencial para que a EA na escola não seja tratada como uma disciplina a mais voltada para as ciências biológicas. Os problemas ambientais não se restringem apenas à proteção da vida, mas dizem respeito à qualidade da vida.

A inserção da EA nas matrizes curriculares dos PPPs deveria sinalizar ações transformadoras, não só trazendo questionamentos sobre os complexos problemas ambientais, suas causas e seus efeitos, mas também considerando aspectos políticos, sociais, econômicos e culturais, e a formação crítica dos atores envolvidos. A EA deve estar pautada em um contexto sociocultural e econômico, para que possa ser trabalhada de forma interdisciplinar, baseada num currículo político-pedagógico, no qual o indivíduo possa ter um conhecimento epistemológico e possa se apropriar da problemática ambiental, intervindo de forma consciente e dialógica no mundo.

A formação do individuo só faz sentido se pensada em relação com o mundo em que ele vive e pelo qual é responsável. Na educação ambiental esta tomada de posição de responsabilidade pelo mundo em que vivemos, inclui ai responsabilidade com os outros e com o ambiente (Carvalho, 2004, p. 156).
O currículo para a EA deve estar pautado na formação de agentes transformadores, capazes de pensar e agir criticamente. A escola, nesse sentido, deve estar aberta para discussões pertinentes à EA, desempenhando seu papel de espaço de cidadania, contribuindo para a formação de cidadãos éticos e comprometidos com a humanização das relações entre homem e natureza.

Conforme Lima (2009), a EA sofreu forte influência das ciências naturais, apresentando uma dissociação entre os aspectos biológicos/ ecológicos e os aspectos políticos e sociais do ambientalismo. Assim, a EA conservadora se baseia na sensibilidade do homem com relação à natureza, compreendendo o meio ambiente em seus aspectos naturais, dissociados dos aspectos, políticos, sociais e econômicos. Segundo Layragues (2012), a EA conservacionista se refere à pauta verde, tendo como objetivo desenvolver na criança, desde a tenra idade, o amor pela natureza, pois, nessa abordagem, o ser humano é visto como destruidor da natureza.

A educação ambiental critica surge em um contexto de movimentos educacionais democráticos e emancipatórios, com ideais contrários à educação tecnicista, baseada numa abordagem conservadora, com vistas a simples transmissão de conhecimentos. (Carvalho, 2004). Essa abordagem critica tem um caráter transformador, popular, emancipatório e dialógico (Loureiro, 2000; Lima, 2009).

Carvalho (2004, pp. 18-19) compreende a EA critica como uma "mudança da valores e atitudes, contribuindo para a formação de um sujeito ecológico". Nesse sentido, a EA crítica é capaz de analisar os problemas socioambientais por meio da reflexão, do diálogo e da aquisição de múltiplos conhecimentos.

\section{Método}

O presente estudo é de natureza qualitativa, descritiva e exploratória. Foram utilizadas como instrumentos para a coleta de dados entrevistas com 27 (vinte e sete) professores, de 4 (quatro) escolas públicas de ensino fundamental, localizadas em um município do sudoeste do estado da Bahia. Além disso, foi também utilizada a análise documental dos projetos político-pedagógicos dessas escolas. 
Para a análise dos dados documentais, os PPPs de cada escola foram organizados de modo que fosse possivel levantar as seguintes questões: (a) concepção de currículo escolar; (b) existência de matrizes curriculares para a EA nos anos iniciais do ensino fundamental; e (c) nivel de participação e conhecimento dos professores com relação à inserção de matrizes curriculares nos referidos documentos.

Após a organização documental dos PPPs, foi elaborado um corpus textual composto por todos os conteúdos encontrados nos referidos documentos. Esse corpus foi inserido no IRAMUTEQ, que é um software livre, voltado para análises estatísticas de dados textuais, desenvolvido por Pierre Ratinaud (2009). Esse software produz diversas análises lexicais, tais como: análise estatística, lexicográfica, de especificidade de grupos, classificação hierárquica descendente (CHD), análise de similitude e nuvens de palavras, contribuindo para análises de diversos corpus existentes em estudos das áreas das ciências humanas e sociais, sobretudo com corpora textuais densos.
Os textos dos PPPS foram classificados em categorias, e foram encontradas cinco classes de análise. Dessas, foram analisadas três classes, que relacionam à temática ambiental encontrada nos PPPs.

Os dados foram triangulados. Segundo Minayo (2010), na realização de pesquisas qualitativas e quantitativas, a técnica da triangulação consiste na análise "do contexto, da história, das relações, das representações (...) visão de vários informantes e o emprego de uma variedade de técnicas de coleta de dados que acompanhe o trabalho de investigação" (Minayo, 2010, pp. 28-29). Para a análise de triangulação realizada neste estudo, visando ampliar o universo informacional em torno do objeto de pesquisa, foram utilizadas entrevistas e coleta de informações.

\section{Resultados e discussão}

Na análise realizada por meio do software IRAMUTEQ, os segmentos de texto dos PPPs compuseram 5 (cinco) classes de palavras (Figura 1), conforme representado no dendograma a seguir

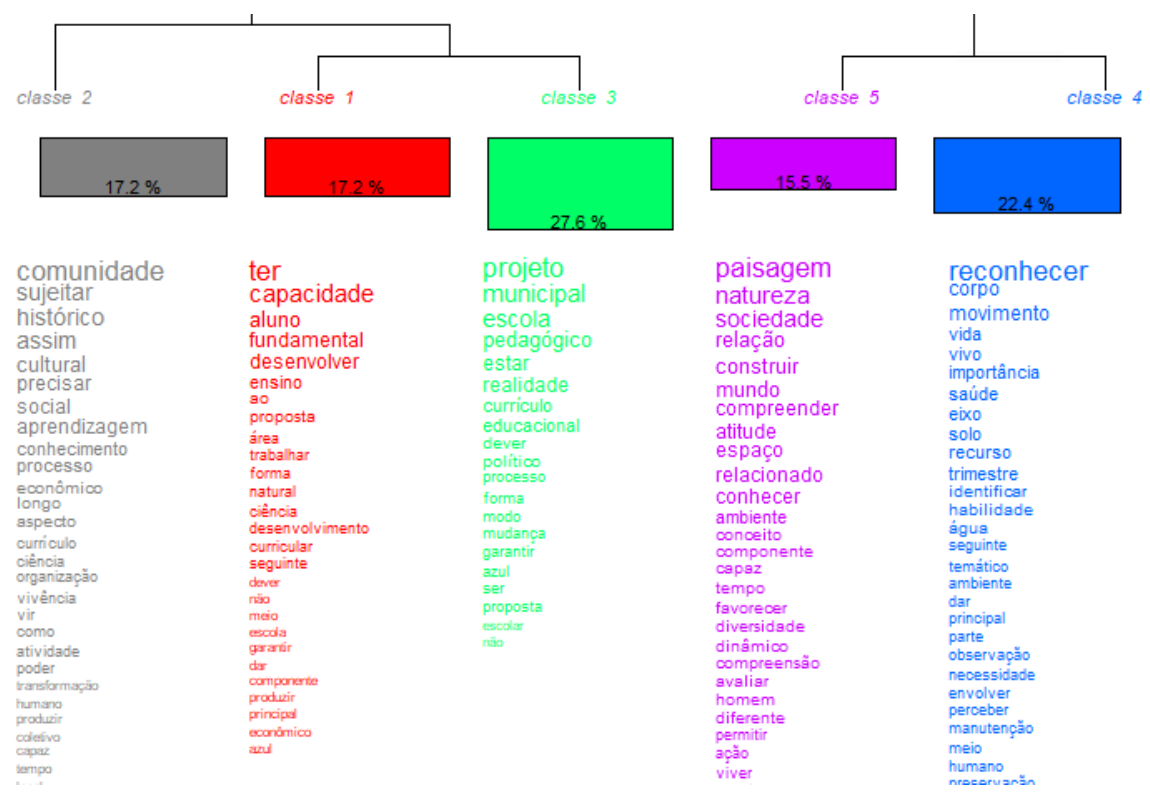

Figura 1 - Dendograma de classe de palavras - Classificação Hierárquica Descendente. Fonte: Elaborado a partir do software IRAMUTEQ, 2017

Na análise do dendograma, as palavras mais recorrentes de cada classe são, nesse corpus textual, as mais frequentes relacionadas aos projetos político-pedagógicos das escolas. Estão apresentados em forma de listas, nas quais as palavras mais recorrentes são encontradas em fonte maior, enquanto as palavras que aparecem com menor frequência são apresentadas com letra menor. É importante ressaltar que os textos dos PPCs foram divididos em classes, por similitude. 
Partindo das palavras e dos contextos em que se encontram, foi possivel construir temas e subtemas de cada classe apresentada. Observa- -se no Quadro 1, a seguir, os temas e subtemas presentes nas três classes analisadas.

Quadro 1 - Temas e subtemas referentes aos projetos político-pedagógicos de escolas municipais

\begin{tabular}{|l|l|l|}
\hline $\begin{array}{c}\text { Classe de } \\
\text { Palavras }\end{array}$ & \multicolumn{1}{|c|}{ Temas } & \multicolumn{1}{c|}{ Subtemas } \\
\hline Classe 01 & $\begin{array}{l}\text { Proposta curricular da temática ambiental na } \\
\text { visão "ciências naturais" }\end{array}$ & $\begin{array}{l}\text { Curriculo escolar na perspectiva } \\
\text { ambiental entre "ciências naturais" }\end{array}$ \\
\hline Classe 04 & Proposta curricular do PPP da escola com EA & $\begin{array}{l}\text { Curriculo escolar na perspectiva do } \\
\text { "cuidado" e "preservação" ambiental }\end{array}$ \\
\hline Classe 05 & $\begin{array}{l}\text { Proposta curricular da temática ambiental na } \\
\text { visão "natureza e sociedade" }\end{array}$ & $\begin{array}{l}\text { Curriculo escolar na perspectiva } \\
\text { ambiental entre "natureza e sociedade" }\end{array}$ \\
\hline
\end{tabular}

Fonte: Elaborado pelas autoras, 2018.

Neste artigo, apresenta-se a análise de três das cinco classes encontradas e que apresentam relação com os PPPs e a temática EA.Foram construidos mapas mentais das classes analisadas, para fins de análise.

\section{Classe 1: proposta curricular da temática} ambiental na visão de "ciências naturais"

Os PPPs analisados afirmam que a matriz curri- cular está em conformidade com a Base Nacional Comum Curricular, enfatizando a temática ambiental dentro do campo das ciências naturais. Essa perspectiva aponta para uma EA apenas sob o ponto de vista do meio ambiente, apresentando uma perspectiva conservacionista de educação ambiental, como apresentado na Quadro 1, que ilustra essa abordagem a partir do fragmento de texto do PPP 3.

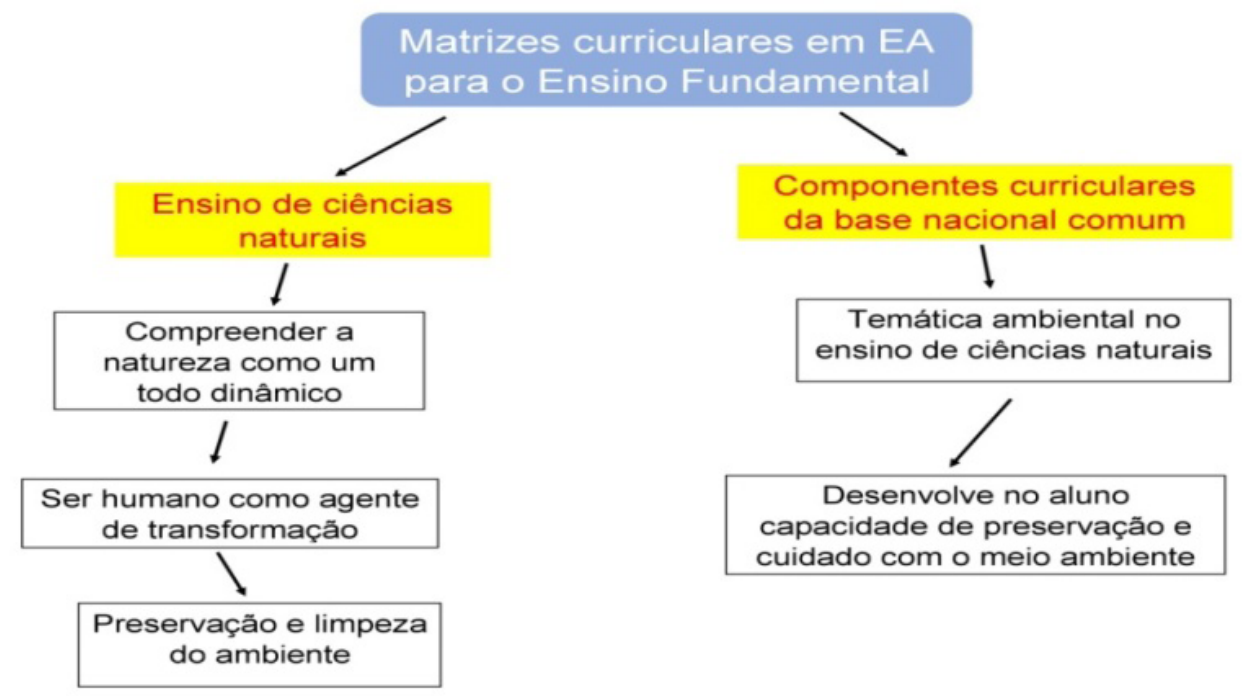

Figura 2 - Classe 1: "Proposta curricular da temática ambiental na visão 'ciências naturais'".

Fonte: Elaborado pelas autoras, 2018.

O ensino de Ciências Naturais deverá se organizar de forma que o aluno tenha desenvolvido as seguintes capacidades: Compreender a natureza como um todo dinâmico e o ser humano em sociedade como agente de transforma- ções do mundo em relação essencial com os demais seres vivos e outros componentes do ambiente. (Brasil, 1997, p. 35, como citado em PPP da Escola Municipal Professora Ita David de Castro, 2016, pp. 47-48).) 
Devido ao fato de os PCNs apresentarem a temática ambiental de forma transversal, perpassando todos os conteúdos e as disciplinas do curriculo, não faz sentido essa temática ser trabalhada apenas na área de ciências naturais, pois deve envolver todas as disciplinas, em uma perspectiva holistica.

Os PCNs confirmam que a EA não deve estar voltada apenas para o cuidado e a preservação da natureza, mas deve "contribuir para a formação de cidadãos conscientes, aptos a decidir e atuar na realidade socioambiental, de um modo comprometido com a vida, com o bem-estar de cada um e da sociedade local e global" (Brasil, 1998, p. 187).

Essa proposta de ensino, segundo os PCNs, visa desenvolver no aluno habilidades e competências para transformar os conhecimentos de forma critico-reflexiva, visando à reconstrução e à transformação, tornando-os capazes de intervir na problemática ambiental e na criação de soluções viáveis para os problemas ambientais.

Dessa forma, os conteúdos passam a ter outro enfoque curricular, contemplando a problemática ambiental vivenciada pelos sujeitos do processo de ensino-aprendizagem, voltada para o seu contexto social, cultural, econômico e político.

\begin{abstract}
Os PCNs propõem uma mudança de enfoque em relação aos conteúdos curriculares: ao invés de um ensino em que o conteúdo é visto em si mesmo, o que se propõe é um ensino em que o conteúdo é visto como meio para que os alunos desenvolvam as capacidades que the permitem produzir e usufruir dos bens culturais, sociais e econômicos. (PPP - Escola Municipal Professora Ita David de Castro, 2016, p. 45)
\end{abstract}

Nos discursos dos professores, ao contrário do que está registrado no texto de três PPPs que tratam a EA como integrante das ciências naturais, encontram-se discursos que evidenciam a EA de forma interdisciplinar e transversal, perpassando por todas as disciplinas: "E muito importante a inclusão da EA no currículo escolar, pois é um tema transversal que deve perpassar por todas as disciplinas" (Rosa, comunicação pessoal, 29 set. 2017).

\section{Classe 4: proposta curricular do PPP da escola com EA}

A análise da Classe 4, sistematizada por meio do mapa mental da Figura 3, evidencia a proposta curricular em EA no PPP das escolas que adotam uma perspectiva conservacionista, na qual a EA é vista em seus aspectos naturais.

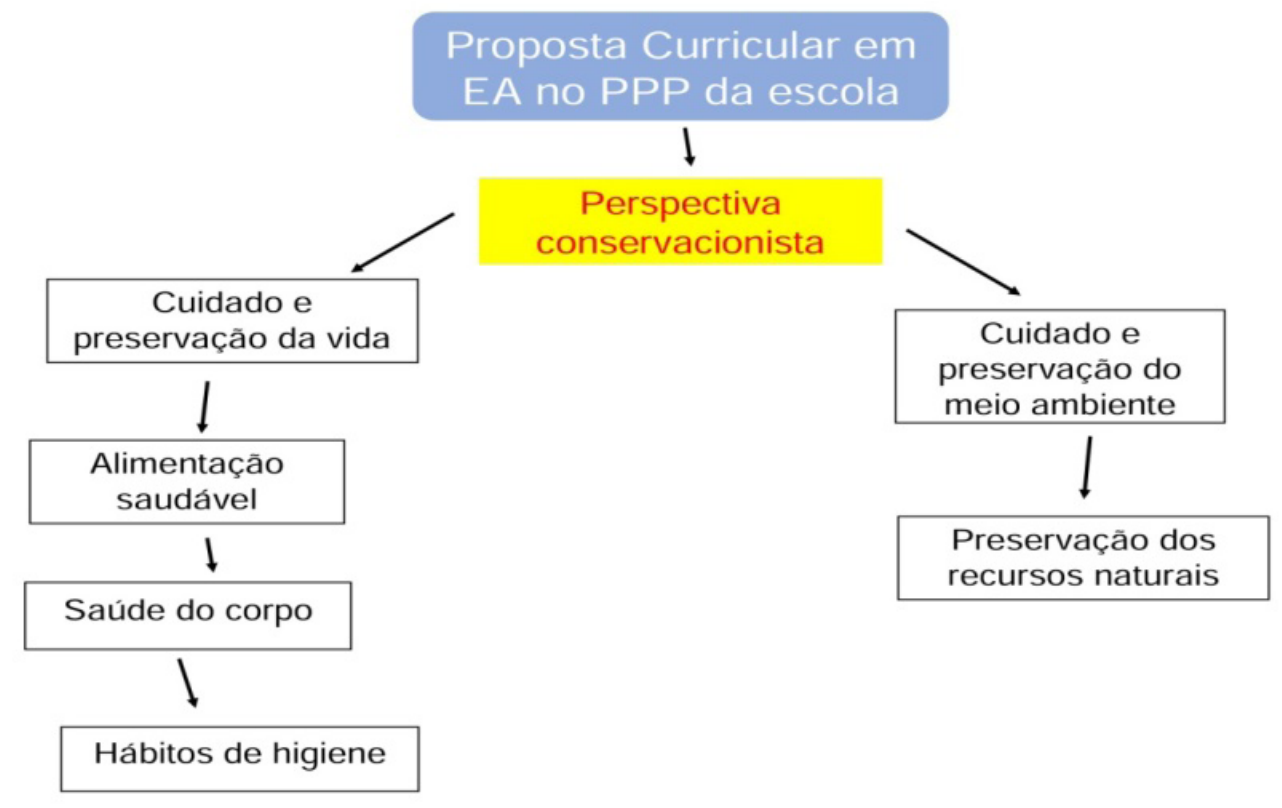

Figura 3 - Classe 4: Proposta Curricular do PPP da escola com EA. Fonte: Elaborado pelas autoras, 2018. 
Esse caráter conservacionista se estabelece a partir da sensibilidade humana em relação à natureza, sem compreensão das questões sociais nela implicadas, como se evidencia no trecho a seguir:

Dentro do eixo temático ambiente e vida, para o primeiro trimestre são trabalhadas as seguintes habilidades; construir conceitos iniciais de Meio Ambiente; Identificar semelhanças e diferenças entre os diversos ambientes; Reconhecer que um ambiente é composto por seres vivos e não vivos; Reconhecer a importância da interação dos seres vivos entre si na manutenção do equilibrio ambiental; Perceber a distribuição da água no planeta e reconhecer a necessidade de preservação dos recursos hídricos. (PPP. Escola Municipal Isa Medeiros, 2017, p. 50)

Essa abordagem conservacionista trata o ser humano como "destruidor da natureza", sem uma preocupação social. Nesse contexto, segundo Reigota (1995, p. 74), "(...) o homem é enquadrado como a nota dissonante com Meio Ambiente, ou seja, o componente depredador por excelência. Os elementos com maior incidência são os abióticos (água, ar, solo) e os bióticos, genericamente seres vivos".

Na perspectiva conservacionista, valoriza-se a compreensão da problemática ambiental considerada sob a ótica da mudança de atitudes e de comportamentos dos seres humanos, que devem, por sua vez, estarem voltados para o "cuidado e a preservação do Meio Ambiente", pois o ser humano deve reconhecer a "(...) importância da interação dos seres vivos entre si na manutenção do equilibrio ambiental" (PPP. Escola Municipal Isa Medeiros, 2017, p. 51).

Nota-se que tanto a concepção da EA abordada no PPP da escola quanto o discurso da professora demonstram uma visão conservacionista, em que a EA é vista como o "cuidado e a preservação ambiental", e tratada de forma fragmentada e pontual nas práticas escolares cotidianas. A fala da professora cita que "Educação Ambiental é a educação voltada para a conscientização das pessoas a respeito do cuidado com o Meio Ambiente, da proteção, das questões que estão ligadas a... até o seu ambiente de convivência" (...) (Orquidea, comunicação pessoal, 21 set. 2017).

\section{Classe 5: Proposta curricular da temática} ambiental na visão "natureza e sociedade"

Apenas o PPP de uma escola traz essa abordagem. O PPP da Escola Papagaio do Papo Azul aborda, em seu currículo escolar, a perspectiva ambiental entre "natureza e sociedade", considerando a EA numa inter-relação e interdependência entre o meio natural e o meio social: "Compreender a natureza como um todo dinâmico e o ser humano em sociedade, como agente de transformação do mundo em que vive é relação essencial com os demais seres vivos e outros componentes do ambiente" (Brasil, 1997, p. 31).

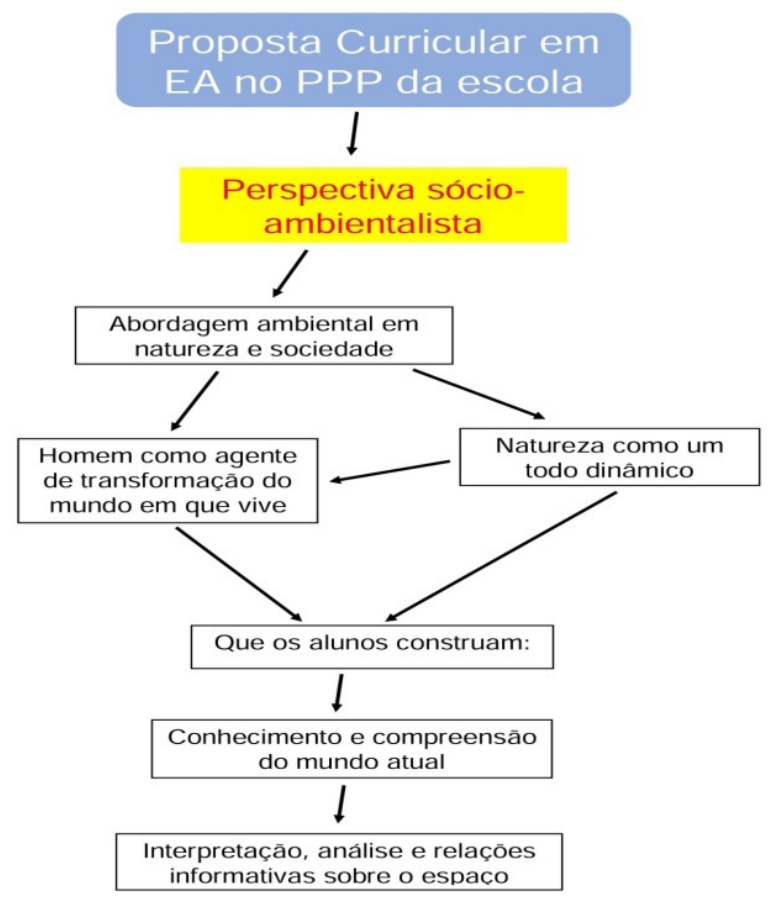

Figura 4 - Classe 05: Proposta Curricular da temática ambiental na visão "natureza e sociedade".

Fonte: Elaborado pelas autoras, 2018.

A inserção da EA na escola, sendo pensada em seus aspectos sociais e naturais, de forma integrada, possibilita uma maior aproximação entre a realidade vivida pelo educando e o seu meio natural, facilitando, dessa maneira, a compreensão e a importância do ambiente natural para a vida em sociedade.

Apesar de o PPP da escola Papagaio do Papo Azul apresentar, em sua matriz curricular, uma proposta de EA pautada em uma visão que con- 
sidera natureza e sociedade, os discursos dos professores evidenciam contradições, no sentido de apresentarem um pensamento reducionista e fragmentado acerca da EA, sinalizando para uma perspectiva ambiental voltada para o "cuidado" e "proteção", conforme pode ser observado no discurso de uma das professoras, que define: "Educação Ambiental é o cuidado e proteção com as plantas, os animais" (Samambaia, comunicação pessoal, 20 set. 2017).

Nos discursos dos professores evidencia-se a falta de oportunidade em vivenciar processos de formação com aquisição de habilidades para o ensino dos problemas socioambientais que afetam o cotidiano, bem como um trabalho pedagógico coletivo e participativo, direcionado aos processos de aprendizagem e competência. O aprofundamento do processo educativo na área ambiental, segundo Carvalho (2004), é condição para uma mudança de mentalidade dos professores como protagonistas da educação, apresentando grande potencial multiplicador para uma EA crítica e transformadora.

\begin{abstract}
A formação do indivíduo só faz sentido se pensada em relação com o mundo em que ele vive e pelo qual é responsável. Na educação Ambiental essa tomada de posição de responsabilidade pelo mundo em que vivemos, inclui a responsabilidade com os outros e com o ambiente. (Carvalho, 2004, p. 156)
\end{abstract}

A escola, nesse sentido, deve ser um espaço aberto para a formação de consciência e para construção de espaço de fala e de escuta dos sujeitos que fazem parte da comunidade escolar. Moreira (2001, p. 75) afirma que "(..) ao discutir ou definir Meio Ambiente, é importante que consideremos as complexas relações existentes na sociedade e entre os diversos elementos da natureza e suas interdependências", ou seja, é necessário que as questões ambientais estejam inter-relacionadas às questões socioambientais, para que, de fato, possam trazer resultados satisfatórios.

Dessa forma, os atores, juntos, podem diagnosticar, problematizar e intervir nos problemas ambientais locais, fortalecendo a participação e o diálogo no âmbito escolar, assumindo, assim, posturas cidadãs

\section{Considerações finais}

Considerando a importância da gestão participativa e os beneficios desse tipo de gestão na educação para o exercício da cidadania e para o desenvolvimento e o crescimento geral da escola, pode-se afirmar que os projetos políticos pedagógicos apontam discursos sobre uma gestão orientada por principios democráticos e caracterizados pelo reconhecimento da importância da participação (consciente e esclarecida das pessoas nas decisões sobre a orientação), organização e planejamento do seu trabalho, e articulação das várias dimensões e dos vários descobrimentos de seu processo de implementação.

Dos quatro PPPs analisados, três documentos apresentam matrizes curriculares que contemplam a EA sob uma perspectiva conservacionista (adoção de comportamento de conservação, visando o não esgotamento dos recursos naturais), que está relacionada, segundo Sauvé (2012), a uma tendência no âmbito da corrente naturalista (contato e afetividade com a natureza), também conhecida como preservacionista (cuidado e preservação ambiental). A EA, neste caso, é discutida apenas em seus aspectos naturais e ambientais, sem a preocupação com os aspectos culturais, sociais e econômicos que estão inter-relacionados.

Apenas um documento aborda a inserção da EA nas matrizes curriculares, a partir de uma visão holística que enreda Natureza e Sociedade. Neste sentido, a questão ambiental no âmbito da perspectiva socioambiental está voltada para uma educação critica, que, segundo Carvalho (2004), contribui para a formação do sujeito, proporcionando e impulsionando mudanças de valores e de atitudes, advindas das relações indivíduo-sociedade, pensados, assim, conjuntamente.

Dessa forma, ao se conceber a EA na perspectiva socioambiental, é possivel reconhecê-la como elemento que formação da cidadania, tal como sugerida por Leff (2010). Segundo o autor, compreender a cidadania significa avaliar noções como pertencimento e identidade coletiva, o que dialoga com a proposta de uma nova forma de encarar a relação do homem com a natureza, 
que seja baseada em uma nova ética, com outros valores morais que sejam basilares para a constituição de cidadãos com consciência local e global.

É importante salientar que, apesar de o projeto político pedagógico da Escola Papagaio Azul abordar a questão ambiental na perspectiva socioambiental, os discursos dos professores dessa escola evidenciam uma contradição entre o que consta no documento o que eles compreendem por EA. Para os professores, a EA é concebida sob o ponto de vista conservacionista, evidenciando também o desconhecimento das matrizes curriculares contidas nesse PPP.

Essa contradição encontrada entre o PPP da escola e o discurso dos professores com relação às questões ambientais demonstra que os docentes apresentam pouco conhecimento sobre a temática ambiental, evidenciando também pouca ou nenhuma participação na construção do documento de cunho político e pedagógico, que é de grande relevância para a organização, o planejamento e a efetivação da ação pedagógica, no que tange à educação ambiental. Um dos desafios da escola, conforme Vasconcelos (2000), é que o PPP se torne necessário e possivel, o que está atrelado ao reconhecimento sobre a legitimidade da construção do documento, assim como do próprio PPP.

Nesse sentido, os resultados da pesquisa evidenciam a necessidade de formação continuada de professores em educação ambiental, em parceria com a Secretaria Municipal de Educação, a Secretaria do Meio Ambiente, as Universidades e com outros órgãos e instituições, de forma que esses profissionais possam, a partir do conhecimento teórico-prático, refletir constantemente sobre a sua prática pedagógica, desenvolvendo o movimento de ação-reflexão-ação, buscando, assim, interagir com seus alunos de forma crítica sobre as questões ambientais, partindo da realidade de vida em que esses sujeitos se encontram.

O estudo deste trabalho não se esgota aqui, mas espera-se que as discussões e as reflexões aqui abordadas sobre as representações sociais de professores em EA, bem como o resultado da análise dos documentos referentes aos PPPs das escolas, com ênfase na EA, possam ampliar as discussões e contribuir para estudos de relevância para a tomada de decisões pertinentes no âmbito escolar, contribuindo para formação de cidadãos crítico-reflexivos.

\section{Referências}

Agenda 21. (2012). Conferência das Nações Unidas sobre o Meio Ambiente e Desenvolvimento. http://Www.org. br.riozo/img/2012/01/agenda21.pdf.

Aranha, M. L. A. (1996) História da Educação (2. ed.). Moderna.

Benincá, E., \& Caimi, F. E. (Orgs.) (2001). Formação de Professores: um diálogo entre a teoria e a prática. UPF.

Constituição da República Federativa do Brasil (16. ed.). (1988). Atlas. http://www.senado.gov.br/legislação/ const/con1988/con1988_05.10.1988/con1988.pdf.

Carvalho, I. C. M. (2004). Educação Ambiental: A formação do sujeito ecológico (4. ed.) Cortez.

Dias, G. F. (1992). Educação Ambiental: Principios e práticas. Gaia.

Dourado, L. F. (2000). A escolha de dirigentes escolares: políticas e gestão da educação no Brasil. In Ferreira, N. S. C. (Org.). Gestão democrática da educação: atuais tendências, novos desafios (pp. 77-95). Cortez.

Layragues, P. P. (2012). Para onde vai a Educação Ambiental? O Cenário político-ideológico da Educação Ambiental brasileira e os desafios de uma agenda politica critica contra hegemônica. Rev. Contemporânea de Educação, 7(14): 398-421.

Leff, E. E. (2010). Epistemologia Ambiental (5. ed.). Cortez.

Lei $n^{\circ} 010172$ de 09 de janeiro de 2001. Aprova o Plano Nacional de Educação e dá outras providências. MEC/ SEF. http://portal.mec.gov.br/arquivos/pdf/L10172.pdf.

Lei $n^{\circ}$ 9.795, de 27 de abril de 1999. Dispõe sobre a Educação Ambiental, institui a Politica Nacional de Educação Ambiental e dá outras providências. MEC/SEF.

Lei $n^{\circ}$ 9.394, de 20 de dezembro de 1996: estabelece as diretrizes e bases da educação nacional. http://WwW. planalto.gov.br/ccivil_03/leis/l.93.94.htm

Lima, G. F. C. (jan./abr. 2009). Educação Ambiental Critica: Do socioambientalismo às sociedades sustentáveis. Educação e Pesquisa, 35(1), 145-163. http://www.scielo. br/pdf/ep/v35n1/a10v35n1.pdf

Loureiro, C. F. B. et al. (2000). Cidadania e Meio Ambiente Construindo os recursos do amanhã. Centro de Recursos Ambientais.

Luck, H. (2008). Gestão educacional: uma questão paradigmática (4. ed., Série: Cadernos de Gestão). Editora Vozes.

Minayo, M. C. S. (2010). Introdução. In M.C.S. Minayo et al. (Org.). Avaliação por triangulação de métodos: Abordagem de Programas Sociais (pp. 19-51). Fiocruz. 
Maria Tereza Rocha Ramos • Patricia Diana Edith Belfort de Souza e Camargo Ortiz Monteiro

A gestão educacional e a inclusão da temática ambiental nos PPPs de escolas públicas municipais

Ministério da Educação (1997). Parâmetros Curriculares Nacionais: Ciências Naturais. MEC/SEF. http://portal. mec.gov.br/seb/arquivos/pdf/livroo4.pdf

Ministério da Educação. (1998). Parâmetros curriculares nacionais: ética. MEC/SEF.

Ministério da Educação. (2018) Base Nacional Comum Curricular (2. versão revista). MEC/SEF. http:// basenacionalcomum.mec.gov.br/documentos/bncc2versao.revista.pdf.

Ministério da Educação. (2008). Plano de Desenvolvimento da Educação. MEC/SEF. http://portal.mec.gov.br/ arquivos/pde/oquee.html.

Moreira, M. F. (2001). Caminhadas Ecológicas como uma nova prática educacional. In Selles, S. E. et al. (Orgs.). Anais do I Encontro Regional de Ensino de Biologia da Regional RJ/ES - Novo milênio, novas práticas educacionais, UFF e SBEnBio RJ/ES, 479-480.

Morin, E. (2000). A cabeça bem-feita: repensar a reforma, reformar o pensamento (7. ed.). Bertrand.

Paro, V. H. (2001). Administração escolar: introdução critica (10. ed.). Cortez.

Projeto Político Pedagógico (2011). Escola Municipal Perícles Gusmão Régis. Vitória da Conquista - BA.

Projeto Político Pedagógico (2016) Escola Municipal Professora Ita David de Castro. Vitória da Conquista - BA.

Projeto Político Pedagógico (2017). Escola Municipal Iza Medeiros. Vitória da Conquista - BA

Reigota, M. (2013). Meio Ambiente e Representação Social. Cortez.

Sander, B. (2005). Políticas Públicas e Gestão Democrática da Educação. Liber Livro Editora.

Sauvé, L. (2000). Para construir um patrimônio de investigación em educación ambiental. Tópicos en Educación Ambiental. 2(5), 51-69.

Shiroma, O. E; Moraes, M. C. M. \& Evangelista, O. (2011). Politica Educacional (4. ed.). Lamparina.

Vasconcelos, C. S. (2002). Coordenação do Trabalho Pedagógico: do Projeto Político-Pedagógico ao cotidiano da sala de aula. Libertad.

Veiga, I. P. A. (2001). Projeto Político Pedagógico: Uma construção possivel. Cortez.

\section{Maria Tereza Rocha Ramos}

Mestre em Educação pela Universidade de Taubaté (UNITAU) em Taubaté, SP, Brasil. Professora do ensino fundamental da rede municipal em Vitória da Conquista, BA, Brasil.

\section{Patricia Diana Edith Belfort de Souza e} Camargo Ortiz Monteiro

Doutora em Ciências Ambientais pela Universidade de Taubaté (UNITAU), em Taubaté, SP. Professora do Programa de Pós-graduação em Educação da Universidade de Taubaté, em Taubaté, SP, Brasil e do Programa de Pós-graduação em Educação da Universidade Estácio de Sá, no Rio de Janeiro, RJ, Brasil.

\section{Endereço para correspondência}

Patrícia Diana Edith Belfort de Souza e Camargo Ortiz Monteiro

Universidade de Taubaté

Rua Visconde do Rio Branco, 210

Centro, 12020-220

Taubaté, SP, Brasil

Os textos deste artigo foram revisados pela Poá Comunicação e submetidos para validação do(s) autor(es) antes da publicação. 